\title{
Neonatal Infectious Disorder
}

National Cancer Institute

\section{Source}

National Cancer Institute. Neonatal Infectious Disorder. NCI Thesaurus. Code C99231.

An infectious disorder that occurs during the neonatal period. Representative examples include streptococcal infection, E.coli infection, and bacterial mening itis. 